\title{
Carbapenemase Producers Among Extensive Drug-Resistant Gram-Negative Pathogens Recovered from Febrile Neutrophilic Patients in Egypt
}

This article was published in the following Dove Press journal:

Infection and Drug Resistance

\author{
Samar S Mabrouk' \\ Ghada R Abdellatif' \\ Mona R El-Ansary (D) ${ }^{2}$ \\ Khaled M Aboshanab (1D ${ }^{3}$ \\ Yasser M Ragab ${ }^{4}$ \\ 'Department of Microbiology, Faculty of \\ Pharmacy, Ahram Canadian University \\ (ACU), 6th of October, Giza, Egypt; \\ ${ }^{2}$ Department of Biochemistry, Modern \\ University for Technology and \\ Information (MTI), Cairo, Egypt; \\ ${ }^{3}$ Department of Microbiology and \\ Immunology, Faculty of Pharmacy, Ain \\ Shams University (ASU), Cairo, Egypt; \\ ${ }^{4}$ Department of Microbiology \& \\ Immunology, Faculty of Pharmacy, Cairo \\ University (CU), Cairo, Egypt
}

Purpose: This study aimed to detect the prevalence of carbapenemase producers (CPs) among extensive drug-resistant (XDR)-carbapenemase producing Gram-negative bacteria (GNB) recovered from various clinical specimens of hospitalized neutrophilic febrile patients in two major tertiary care hospitals in Egypt.

Methods: Standard methods were used to evaluate the antimicrobial susceptibility of clinical isolates according to the guidelines of the Clinical and Laboratory Standards Institute (CLSI). Phenotypic and genotypic analysis of CPs were carried out and statistically analyzed using standard methods.

Results: Three hundred and forty-two GNB were obtained from 342 clinical specimens during the period of the study, where $162(47 \%)$ were enterobacterial isolates, including, 63 (18.4\%) Escherichia coli, 87 (25.4\%) Klebsiella spp., 5 (1.46\%) Enterobacter cloacae, 5 (1.46\%) Salmonella spp. and 2 (0.6\%) Proteus and 180 (53\%) were non-fermentative bacilli including, 129 (37.7\%), Acinetobacter baumannii, and 51 (14.9\%), Pseudomonas spp. Out of the 342 GNB, 188 (54.9\%) isolates were multi-drug resistant (MDR). Of these, 52 (27.6\%) were XDR as well as CPs as confirmed phenotypically. The MIC of imipenem against the XDR GNB against showed either low (11 isolates; $21.1 \%$; MIC range $=4-32 \mu \mathrm{g} / \mathrm{mL}$ ) or high levels of resistance (41 isolates; 78.8\%; MIC range $=64-\geq 1024)$. The most prevalent carbapenem resistance (CR) genes were blaKPC (63.5\%) followed by blaOXA-48 $(55.7 \%)$ and blaVIM (28.8\%). No significant association could be observed between the MIC level and the presence of $\mathrm{CR}$ genes ( $P$ value $>0.05$ ).

Conclusion: High prevalence of MDR (54.9\%) and XDR (27.6\%) GNB pathogens associated with high levels of resistance to carbapenems were observed. All XDR GNB were CPs and tested positive for at least one of the CR genes. However, most of them (78.8\%) showed a high level of $\mathrm{CR}$ (MIC range $=64-\geq 1024$ ) with no significant association with the CR genes.

Keywords: carbapenem resistance, carbapenemases, MDR, XDR, Gram-negative pathogens

\section{Introduction}

The development and dissemination of XDR carbapenem-resistant (CR) Gramnegative bacteria (GNB) is considered a serious hazard to human health globally. ${ }^{1-4}$ The development of $\mathrm{CR}$ is receiving remarkable attention nowadays as carbapenem antibiotics are viewed as the last line of defense against severe multidrug-resistant infections. ${ }^{5-7}$.
Correspondence: Khaled M Abosh
Department of Microbiology and Immunology, Faculty of Pharmacy, Ain Shams University, Organization of African Unity St., PO: II 566, Abbassia, Cairo, Egypt

Tel +20225082595

Fax +20224051107

Email aboshanab2012@pharma.asu.edu.eg
Infection and Drug Resistance 2020:13 31/3-3124 
CR could be due to decreased outer membrane permeability associated with an overproduction of AmpC $\beta$-lactamases, generation of extended-spectrum betalactamases (ESBLs) and overexpression of class A, $\mathrm{B}$ and $\mathrm{D}$ carbapenemase enzymes. These enzymes include Klebsiella pneumoniae carbapenemase (blaKPC), Verona integron encoded metallo- $\beta$ lactamase (blaVIM), New Delhi metallo- $\beta$-lactamase (blaNDM), imipenemase (blaIMP) and oxacillinases (blaOXA-48). This remains the most clinically important mechanism that drives the emergence of resistance among GNB worldwide and is involved in most of the nosocomial outbreaks recently. ${ }^{8,9}$

Due to the consequences of the high morbidity and mortality rates and the high chance of large-scale dissemination of CR particularly via transmissible genetic, an expeditious detection of CPs is of a crucial importance to limit this threatening public health crisis. ${ }^{10,11}$ Also, the emergence of XDR GNB particularly those that are CPs has elevated dramatically in the last years imposing a global concern. ${ }^{10,11}$ Moreover, the treatment options for pyogenic infection caused by XDR GNB pathogens became very limited and scarce, particularly for pediatrics. ${ }^{10,11}$ The febrile neutrophilic patients are characterized by having leukocytosis where total leucocyte count is above 11,000 white blood cells $/ \mu \mathrm{L}$ as well as fever with an oral temperature $>38^{\circ} \mathrm{C}$ for at least 1 hour. These parameters are indicative of pyogenic infections. ${ }^{11}$ Thus, the aim of our current study is to highlight the prevalence, phenotypic and genotypic characteristics of CPs obtained from neutrophilic febrile patients admitted to two major Tertiary Care Hospitals in Egypt.

\section{Methods}

\section{Collection and Examination of Clinical}

\section{Isolates}

A total of 342 non-duplicate Gram-negative clinical isolates discharged from the Microbiology laboratories of New Kasr El Aini and El Demerdash Tertiary Care Hospitals, Cairo, Egypt were collected over a period of 6-month, between April and September 2019. The study was approved by the Faculty of Pharmacy Cairo University Ethical Committee Nr. MI (2418) in April, 2019. Both oral and written informed consent were obtained from patients or parents of the patients after clarifying them with the purpose of the study which was carried out in accordance with the guidelines outlined in the Declaration of Helsinki. Based on the hospital records, the isolates were recovered from 342 clinical specimens obtained from febrile neutrophilic patients $(>11,000$ white blood cells/microL with oral temperature $>38^{\circ} \mathrm{C}$ over at least 1 hour $)$ including, urine $(\mathrm{n}=118)$, sputum $(\mathrm{n}=112)$, pus $(\mathrm{n}=42)$, blood $(\mathrm{n}=17)$, stool $(\mathrm{n}=11)$, and others including catheter tips and bronchial lavage $(n=42)$. The patients' age ranged from 1 to 65 years. There were $158(46 \%)$ male including the age ranged $1-20$ year $(95 ; 28 \%), 21-40$ year $(20 ; 6 \%)$, 41-66 year $(43 ; 12.5 \%)$ and $184(54 \%)$ were females including the age ranged $1-20$ year $(112 ; 33 \%)$, $21-40$ year $(23 ; 7 \%), 41-66$ year $(49 ; 14 \%)$. Isolates were identified macroscopically, microscopically, and biochemically according to Bergey's manual of determinative bacteriology. ${ }^{12}$ The bacterial identification was confirmed using the MicroscanR WalkAway-96 Plus auto-identification system (Beckman Coulter, Miami, FL, USA). No specific exclusion criteria were applied and all isolates were collected on routine workdays. To confirm the identification of isolates, our data were compared to the hospital's data records.

\section{Antimicrobial Susceptibility Tests}

The antibiotic susceptibility tests were performed according to Kirby-Bauer method using a panel of 13 antibiotic disks including amoxicillin/clavulanic acid $(20 \mu \mathrm{g} / 10 \mu \mathrm{g})$, amikacin $(30 \mu \mathrm{g})$, aztreonam $(30 \mu \mathrm{g})$, cefoxitin $(30 \mu \mathrm{g})$, ceftriaxone $(30 \mu \mathrm{g})$, ciprofloxacin $(5 \mu \mathrm{g})$, levofloxacin $(5 \mu \mathrm{g})$, imipenem $(10 \mu \mathrm{g})$ meropenem $(10 \mu \mathrm{g})$, ertapenem $(10 \mu \mathrm{g})$, imipenem $(10 \mu \mathrm{g})$, sulphamethoxazole/trimethoprim $(25 \mu \mathrm{g})$, and doxycycline $(30 \mu \mathrm{g})$ were tested. Kirby-Bauer test was carried out on Mueller-Hinton agar plates one time for all tested isolates followed by measurements of the inhibition zone diameters. MDR and XDR isolates were defined based on the international standard criteria as previously reported. ${ }^{13}$ The XDR isolates that revealed resistance pattern to any of the carbapenems tested were potentially pointed out as carbapenem-resistant and accordingly, were selected to detect their MIC against imipenem by broth microdilution method according to CLSI guidelines, 2019. ${ }^{14}$ The broth microdilution test was done in triplicate. Enterobacteriaceae isolates that revealed MIC $\geq 4 \mu \mathrm{g} / \mathrm{mL}$ and non-fermentative bacilli isolates that revealed $\mathrm{MIC} \geq 8 \mu \mathrm{g} / \mathrm{mL}$ for imipenem were considered carbapenem-resistant isolates with great 
potential for carbapenemase production according to CLSI, 2019. ${ }^{14}$ Quality control was monitored by using E. coli ATCC $25922^{\mathrm{TM}}$ reference strain.

\section{Phenotypic Detection of CPs}

Modified Carbapenem Inactivation Method (mCIM) $\mathrm{mCIM}$ for detection of CPs using readily available laboratory reagents was recommended by the CLSI guidelines in 2019. The test was performed in duplicates on XDR GNB isolates that were potentially CPs. A meropenem disk was briefly immersed in a suspension of tested isolate and incubated for at least 4 hours. Consequently, the disk was transferred to an inoculated plate with $E$. coli ATCC $25922^{\mathrm{TM}}$. After an overnight incubation, the tested isolates showing a zone of inhibition between 6 and $15 \mathrm{~mm}$ or colonies were present within 16-18 $\mathrm{mm}$ were considered CPs. On the other hand, isolates showing a zone of inhibition greater than or equal to $19 \mathrm{~mm}$ were not considered CPs. ${ }^{14}$

\section{Combined Disk Test}

In order to detect metallo-beta lactamases (MBLs) production, combined disk test was performed. About, 0.5 McFarland standard adjusted overnight culture was spread over the surface of Mueller-Hinton agar plate using a cotton swab. Two disks, one is imipenem and the other is imipenem/ethylenediaminetetraacetic acid (EDTA) were laid on the surface of the agar at a distance of $4-5 \mathrm{~cm}$ from each other using sterile forceps. After an overnight incubation, the enhancement of inhibition zone $(\geq 7 \mathrm{~mm}$ ) of the IPM-EDTA disk compared to imipenem disk alone was considered positive for the presence of MBLs. This test was done in duplicates to ensure the reproducibility of results. ${ }^{15}$

\section{Blue-Carba Test}

The Blue-carba test can detect all CPs directly from bacterial culture with $100 \%$ sensitivity and specificity. This test was carried out as previously reported by Pires et al. ${ }^{16}$ Duplicates of the test were carried out on the promising CPs isolates to give more reproducible results.

\section{Molecular Detection of Genes Coded for Carbapenemases}

DNA of phenotypically confirmed XDR CP isolates was extracted using the Genomic DNA Purification Kit (Thermo Fisher Scientific, USA) according to the manufacturer's instructions and was used as template for PCR using the appropriate primers synthesized by Macrogen ${ }^{\circledR}$. PCR amplification was carried out using the annealing temperatures (Ta) and appropriate primers of blaIMP, blaKPC, blaNDM, blaOXA-48, and blaVIM genes as shown in Table 1. Using agarose gel electrophoresis, the amplified PCR products were analyzed and the interpretation of the size of DNA fragments was done via comparing to a $1000 \mathrm{bp}$ DNA ladder (GeneRuler $1 \mathrm{~kb}$ ThermoFisher Scientific, USA).

\section{DNA Sequencing of PCR Amplicons}

QIA quick PCR Purification Kit (Qiagen) was used to purify the PCR products extracted from the agarose gel, and then they were sequenced using ABI 3730xl DNA sequencer from the forward and reverse directions by the CliniLab Co, Egypt. The resulted sequences were assembled into a final consensus sequence using the Staden Package program version 3 (http://staden.source forge.net/). The open reading frames (ORFs) were analyzed using FramePlot 2.3.2 (http://www.nih.go.jp/ jun/ cgi-bin/frameplot.pl), annotated, and submitted into the NCBI GenBank database under the accession codes MT185944, MT185945 and MT185946:

\section{Statistical Analysis}

Statistical analysis including descriptive statistics, frequency tables, and cross-tabulations was performed using Statistical Package for the Social Sciences software IBM ${ }^{\circledR}$ SPSS ${ }^{\circledR}$ version 20 (SPSS Inc., Chicago, IL, USA). In order to determine the statistical significance, analysis of the categorical variables was performed using the Chisquare test. A value of $\mathrm{P}<0.05$ was considered statistically significant, and significance was two-sided.

\section{Results}

\section{Identification of Recovered Isolates}

A total of 342 GNB were recovered from the 342 clinical specimens throughout the period of the study. A total of $162(47 \%)$ were enterobacterial isolates, including $63(18.4 \%)$ E. coli, 87 (25.4\%) Klebsiella spp., 5 (1.46\%) E. cloacae, 5 (1.46\%) Salmonella spp. and $2(0.6 \%)$ Proteus. On the other hand, a total of 180 (53\%) were non-fermentative bacilli including, 129 (37.7\%), Acinetobacter (A.) baumannii, and 51 (14.9\%), Pseudomonas spp. Antimicrobial susceptibility tests of the 342 isolates showed that $188(54.9 \%)$ were 
Table I Primer Sequences and Expected Sizes of PCR Products of Carbapenemase Genes

\begin{tabular}{|c|c|c|c|c|c|c|}
\hline $\begin{array}{l}\text { Multiplex/ } \\
\text { MonoplexPCR }\end{array}$ & $\begin{array}{l}\text { Carbapenemase } \\
\text { Genes }\end{array}$ & Forward Primer $\left(5^{\prime}-3^{\prime}\right)$ & Reverse Primer (5'-3') & $\begin{array}{l}\text { Expected } \\
\text { PCR Product } \\
\text { Size }\end{array}$ & $\begin{array}{l}\mathrm{Ta} \\
\left({ }^{\circ} \mathrm{C}\right)\end{array}$ & Reference \\
\hline A & $\begin{array}{l}b l a_{\mathrm{KPC}} \\
b l a_{\mathrm{NDM}}\end{array}$ & $\begin{array}{l}\text { TGTCACTGTATCGCCGTC } \\
\text { GGTTTGGCGATCTGGTTTTC }\end{array}$ & $\begin{array}{l}\text { TATTTTTCCGAGATGGGTGAC } \\
\text { CGGAATGGCTCATCACGATC }\end{array}$ & $\begin{array}{l}331 \mathrm{bp} \\
621 \mathrm{bp}\end{array}$ & 50 & $\begin{array}{l}{[17]} \\
{[18]}\end{array}$ \\
\hline B & $\begin{array}{l}\text { bla } \\
\text { bla } a_{\mathrm{OXA}-48}\end{array}$ & $\begin{array}{l}\text { TCTACATGACCGCGTCTGTC } \\
\text { GCGTGGTTAAGGATGAACAC }\end{array}$ & $\begin{array}{l}\text { TGTGCTTTGACAACGTTCGC } \\
\text { CATCAAGTTCAACCCAACCG }\end{array}$ & $\begin{array}{l}748 \mathrm{bp} \\
438 \mathrm{bp}\end{array}$ & 52 & $\begin{array}{l}{[17]} \\
{[19]}\end{array}$ \\
\hline C & $b a_{\mid M P}$ & CTACCGCAGCAGAGTCTTTG & AACCAGTTTTGCCTTACCAT & $587 \mathrm{bp}$ & 56 & {$[17]$} \\
\hline
\end{tabular}

Notes: $\mathrm{A}$ and $\mathrm{B}$ are multiplex PCR; $\mathrm{C}$ is a monoplex of imp detection.

Abbreviation: $\mathrm{Ta}\left({ }^{\circ} \mathrm{C}\right)$, annealing temperature.

multidrug resistant (MDR), among these, 52 isolates (15.2\%) were XDR-CPs.

\section{Antimicrobial Susceptibility Testing and Data Analysis}

Table 2 shows the antibiotic susceptibility patterns of the GNB isolates. Out of the 342 GNB; 188 (54.9\%) isolates were MDR. The MDR GNB isolates were $A$. baumannii (86; 45.7\%), K. pneumoniae $(50 ; 26.6 \%)$, E. coli (30; $16 \%)$, P. aeruginosa (18; 9.6\%), E. cloacae $(3 ; 1.5 \%)$ and Salmonella spp. (1; 0.5\%). Out of the 188 MDR GNB, 52 (27.6\%) exhibited resistance to all of the tested antimicrobial agents; however, they remained sensitive to only one or two and therefore, were categorized as XDR GNB. Furthermore, all of XDR GNB isolates were CPs. As shown in Table 3, the broth microdilution method was used to determine the MIC of the 52 (27.6\%) XDR GNB against imipenem, and based on the value of MIC, the XDR GNB were categorized into 2 categories; low-level resistance (11 isolates; $21.1 \%$; MIC range $=4-32 \mu \mathrm{g} / \mathrm{mL})$ and high-level resistance (41 isolates; 78.8\%; MIC range $=64-\geq 1024$ )

\section{Phenotypic Detection of XDR GNB}

As shown in Table 4, the carbapenemase enzyme producing ability of the XDR GNB ( $\mathrm{n}=52)$ isolates was phenotypically determined using the modified carbapenem inactivation method (m CIM), blue-carba and the combined disk tests.

\section{PCR Amplification of CPs}

The extracted DNA of each of the 52 XDR GNB isolates (CPs) was used as a template for PCR amplification of blaIMP, blaKPC, blaNDM, blaOXA-48, and blaVIM carbapenemase genes.
The results of multiplex PCR revealed that blaKPC was amplified in $33(63.5 \%)$ isolates (15 A. baumannii, 9 Klebsiella spp. 5 Pseudomonas spp, and 3 E. coli and 1 E. cloacace), followed by blaOXA-48 that was detected in $29(55.7 \%)$ isolates (13 A. baumannii, 9 Pseudomonas spp., 6 Klebsiella spp., and 1 E. cloacace), followed by blaVIM that was observed in $15(28.8 \%)$ isolates (7 A. baumannii, 5 Klebsiella spp., 2 Pseudomonas spp. and 1 E. cloacace). Agarose gel electrophoresis of the multiplex-PCR amplification of blaKPC/blaNDM and blaoxa48/blaVIM genes of some of the tested XDR GNB isolates are shown in Figures 1S and $\underline{2 \mathrm{~S}}$, respectively. On the other hand, neither blaIMP nor blaNDM was detected in any of the tested XDR isolates. Data summary of both phenotypic and genotypic findings of the XDR GNB ( $\mathrm{n}=52$ ) is tabulated in Table 5.

\section{Statistical Analysis of the Association of MIC Level of Resistance and Carbapenemase Resistant Genes Among XDR GNB Isolates (n-52)}

Statistical analysis has shown that there was no significant association between MIC level of CR (either high- or lowlevel resistance) and blaKPC, blaOXA-48, blaVIM, PCR detected CR genes $(P$ value $>0.05)$. The statistical Pearson chi-square and Likelihood Ratios are shown in Table 6.

\section{Discussion}

CR bacteria have become a major threatening crisis worldwide, which restricts the available therapeutic and treatment options. ${ }^{20}$ Therefore, we aimed in this study to detect the prevalence of GNB carbapenemase producers, after determining their resistance profiles. The clinical isolates were recovered from various clinical specimens of infected patients attending two major 
hospitals in Egypt. The patients were admitted to the hospital suffering from signs and symptoms of acute pyogenic infections including fever (oral temperature $>38^{\circ} \mathrm{C}$ for at least 1 hour). Based on the hospital records, the complete blood count of the respective patients also showed leukocytosis white blood cells $>11,000 / \mu \mathrm{L}$. According to the hospital records, a total of $158(46 \%)$ patients were males in the age range of $1-20$ years $(95 ; 28 \%), 21-40$ years $(20 ; 6 \%), 41-66$ years $(43 ; 12.5 \%)$. On the other hand, a total of 184 $(54 \%)$ was female patients in the age range of $1-20$ years $(112 ; 33 \%), 21-40$ years $(23 ; 7 \%)$, and $41-66$ years $(49 ; 14 \%)$.

The fact that lower respiratory tract infectious diseases are the number one cause of deaths among infectious diseases worldwide was reflected in the predominance of sputum cultures among recovered specimens. ${ }^{21}$

A total of 342 GNB were recovered from the 342 clinical specimens during the period of our study, where $162(47 \%)$ were enterobacterial isolates, including, 63 (18.4\%) E. coli, 87 (25.4\%) Klebsiella spp., 5 (1.46\%), E. cloacae, 5 (1.46\%) Salmonella spp. and $2(0.6 \%)$ Proteus spp.). The remaining 180 (53\%) were nonfermentative bacilli including 129 (37.7\%) A. baumannii and 51 (14.9\%) Pseudomonas spp.

It has been previously reported that the respiratory tract, blood, and urine tubes were the main important sources of $A$. baumannii pathogens. ${ }^{22,23}$ In our study, $129(37.7 \%)$ A. baumannii isolates were recovered and this could explain the predominance of A. baumannii, the most life-threatening pathogen among the recovered GNB isolates in our study. Moreover, this finding is of great medical value and challenge from the medical point of view since $A$. baumannii is one of the difficultto-treat and nosocomial-infection-causing pathogens., this may be due to of its endless capacity to acquire antimicrobial resistance owing to the plasticity of its genome. ${ }^{24}$ Our microbiological data were in consonance with other novel studies that confirmed that Enterobacteriaceae especially, $K$. pneumoniae and $E$. coli together with $A$. baumannii, and $P$. aeruginosa posed the highest hazards among the GNB recovered from respiratory tract infections. ${ }^{25}$ It is disturbing to note that $44.7 \%$ (84 out of 162) of the enterobacterial isolates were considered MDR as they were resistant to three or more antimicrobial classes. Of these, 50 out of $87(57.5 \%)$ were Klebsiella spp., 30 out of 63 (47.6\%) were E. coli, 3 out of $5(60 \%)$ were E. cloacae and 1 out of $5(20 \%)$ was Salmonella spp. Out of the 180 nonfermentative bacilli, 86 out of $129(66.7 \%)$ and 18 out of $51(35.3 \%)$ were MDR from A. baumannii, and Pseudomonas spp., respectively. Accordingly, out of the 342 GNB; 188 (54.9\%) isolates were MDR which is in accordance with previous studies and imposes weak infection control strategies. ${ }^{26,27}$ Despite the fact that the antibiogram analysis of recovered GNB is raising concerns, yet, the overall sensitivity patterns of amikacin, doxycycline and tigecycline ranging from $70 \%$ to $85 \%$ rise as a promising hope.

In addition, the percentage of $\mathrm{CR}$ represented a cause of concern as the disk diffusion method revealed resistant patterns to at least one of the tested carbapenems (imipenem, meropenem and ertapenem) in 40.12\% (65 out of 162) enterobacterial isolates and 57.78\% (104 out of 180) of non-fermentative bacilli. Regarding the wide dissemination of CP GNB with devastating ramifications within clinical settings, its early disclosure is crucial for expeditious employment of infection control measures and choosing an appropriate antimicrobial therapy. CPs were preliminarily screened for the detection of MBLs using a combined disk test. In the present study, 50\% (26 out of 52) of the tested isolates were positive for class B carbapenemase. This revealed that other carbapenemase types, for example, class A and class D oxacilinase (that were not inhibited by EDTA) might be included in the carbapenem-resistance pattern. This was in accordance with the study conducted by Rakhi et al that had reported $50 \%$ in the combined disk test for MBLs production. ${ }^{28}$

In order to comply with the latest guidelines for carbapenemase production, $\mathrm{mCIM}$ and blue-carba tests were further performed for these $52 \mathrm{CP}$ isolates. Results showed that the former test detected 48 (92.30\%), on the other hand, the latter test detected 51 (98.07\%) of $\mathrm{CP}$ isolates. A recent study conducted by Bayraktar et al showed similar results of $92.7 \%$ and $98.1 \%$ for $\mathrm{mCIM}$ and blue-carba test, respectively. ${ }^{29}$ Moreover, the bluecarba test matched the results of another recent study conducted by Cordeiro-Moura et al that reported $97.1 \%{ }^{27}$ Accordingly, we can declare that the bluecarba test revealed a high sensitivity and specificity for the detection of carbapenemase production and hence is viewed as an auspicious method for the rapid detection of CPs among clinical settings. ${ }^{30}$

We then attempted to identify the carbapenemase genes prevalence, which was crucial for the suppression of such 
Table 2 Antimicrobial Resistance Patterns of the Recovered GNB (N=342)

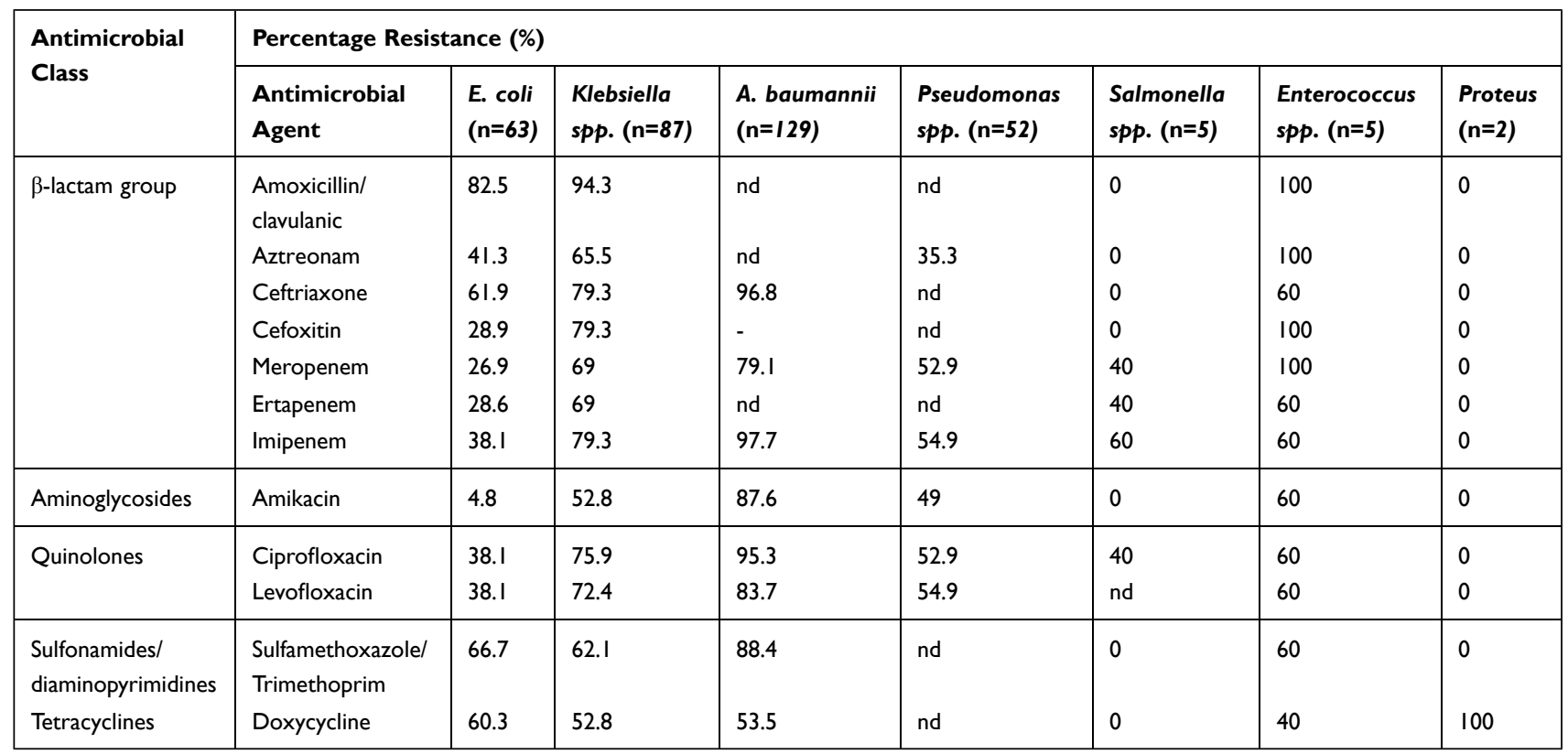

Abbreviation: nd, not determined.

XDR strains within clinical healthcare sets. Following phenotypic screening of CPs isolates (52 isolates), PCR was performed using the genomic DNA of each isolate and the specific primers for each CR gene. The five carbapenemase genes examined in our study were selected based on their prevalence among the GNB and for representing the three major classes of carbapenemases, including, class A serine carbapenemases (blaKPC), class B metallo- $\beta$-lactamases (blaIMP, balNDM and blaVIM) and class D serine carbapenemases (blaOXA-48). ${ }^{2}$

For class A carbapenemases, various genotypes of the $b l a_{\mathrm{GES}}$ gene (coding for blaGES $\beta$-lactamase) comprise a point mutation (G493A), where serine was included instead of glycine which, therefore, displays carbapenemase activity. Reports of GES carbapenemases are rare but increasing steadily particularly because they are plasmidmediated. ${ }^{18,31,32}$

The carbapenemase blaOXA-48 is characterized by high hydrolytic activity to penicillins and low activity towards carbapenems. On the other hand, it is not affected by $\beta$-lactamase inhibitors such as sulbactam and clavulanic acid and therefore of relevant medical importance $^{33,34}$ Other blaOXA $\beta$-lactamase variants including blaOXA-23, blaOXA-24/40, and blaOXA-58 are often detected in Acinetobacter spp., but with low carbapenemase activity as well as lack of inhibition by $\beta$-lactamase inhibitors. ${ }^{35,36}$
This remains the most clinically important mechanism that drives the emergence of resistance among GNB worldwide and is involved in most of the nosocomial outbreaks recently. 8,9

Our results showed that blaKPC was the most predominant $\mathrm{CR}$ gene $(63.5 \%)$ in accordance with a novel study conducted by $\mathrm{Li}$ and his colleagues, ${ }^{37}$ followed by blaOXA-48 23 (55.7\%), then blaVIM 10 (28.8\%). However, blaIMP and blaNDM were not detected in any isolate. On the other hand, our findings were different from another study that was conducted in Zagazig hospital in Egypt, which reported that blaOXA-23 was the most prevalent $(90 \%)$ followed by, blaNDM $(66.7 \%)$ then blaGES (50\%) in CR A. baumannii, respectively. ${ }^{38}$ However, genes coding for blaVIM, blaGES, blaNDM and blaIMP were identified in $50 \%, 40.9 \%, 27.3 \%$ and $18.2 \%$ of CR P. aeruginosa, respectively. ${ }^{38}$ The difference between the respective study and our study could be attributed to other factors such as geographical and patient factors.

Interestingly, $21(40.38 \%)$ out of 52 carbapenemasepositive isolates were found to co harbor 2 carbapenemase genes that were distributed as follows: 19 isolates coharbored blaKPC and blaOXA-48, 1 isolate co-harbored blaKPC and blaVIM and 1 isolate co-harbored blaOXA-48 and blaVIM. Moreover, 4 (7.69\%) isolates co harbored 3 carbapenemase genes that were blaKPC, blaOXA-48 and blaVIM. It was remarkably noticed that the blaKPC was 
Table 3 MIC of Imipenem Against XDR GNB ( $n=52)$

\begin{tabular}{|c|c|c|c|}
\hline \multicolumn{2}{|l|}{ MIC Range $\mu \mathrm{g} / \mathrm{mL}$} & \multirow{2}{*}{$\begin{array}{l}\text { Isolate } \\
\text { Species } \\
\text { E. coli } \\
\text { Klebsiella spp. } \\
\text { A. baumannii } \\
\text { Pseudomonas } \\
\text { spp. }\end{array}$} & \multirow{2}{*}{$\begin{array}{l}\begin{array}{l}\text { No. of } \\
\text { Isolates }\end{array} \\
0 \\
1 \\
8 \\
5\end{array}$} \\
\hline $\begin{array}{l}\text { High level resistance } \\
(n=4 I)\end{array}$ & $\begin{array}{l}512- \\
\geq 1024\end{array}$ & & \\
\hline & 64-256 & $\begin{array}{l}\text { E. coli } \\
\text { Klebsiella spp. } \\
\text { A. baumannii } \\
\text { Pseudomonas } \\
\text { spp. }\end{array}$ & $\begin{array}{l}2 \\
10 \\
10 \\
5\end{array}$ \\
\hline $\begin{array}{l}\text { Low level resistance } \\
(n=11)\end{array}$ & $4-32$ & $\begin{array}{l}\text { E. coli } \\
\text { Klebsiella spp. } \\
\text { A. baumannii } \\
\text { Pseudomonas } \\
\text { spp. } \\
\text { Enterobacter } \\
\text { spp. }\end{array}$ & $\begin{array}{l}1 \\
3 \\
3 \\
3 \\
1\end{array}$ \\
\hline
\end{tabular}

the most predominant gene found in most enterobacterial strains worldwide including Egypt as reported by many studies $^{39-41}$ Although the presence of both blaOXA-48 and blaVIM-1 genes has been previously reported in Egypt in one $E$. coli isolate. ${ }^{42}$ This is the first report confirming the high rate of coexistence of the previously mentioned carbapenemases among Gram-negative bacterial isolates in Egypt. It was not astonishing that the combined disk test was not able to identify 8 blaKPC, 2 blaVIM and 11 blaOXA-48 producing isolates as the latter has no available specific inhibitors. Hence, CDT was not recommended for blaOXA-like gene detection. ${ }^{42,43}$ However, recent investigations are seeking for testing temocillin as a promising inhibitor for blaOXA-48. ${ }^{44}$ Regarding mCIM, negative results were obtained with four isolates producing blaKPC and one isolate producing both blaVIM and blaOXA-48. This was due to the weak hydrolytic activity of blaOXA-48 to meropenem as mentioned in some studies. $^{45-47}$ Never the less, our study showed positive results with blaOXA-48 producing isolates that were not usually identified by phenotypic approaches and this was similar to the results reported by Gauthier et al. ${ }^{48}$ Fortunately, as discussed in other studies and according to our findings, almost all variants of carbapenemase genes managed to be rapidly detected with nearly $100 \%$ sensitivity via the blue-carba test. ${ }^{49,50}$

On the other hand, according to our data $25 \%(n=13)$ of the positive phenotypically tested isolates showed negative results in all five tested primers and this could be attributed to the presence of other carbapenemase genes such as blaSME, blaGES, blaOXA-181, and blaOXA-244 which were not tested in the current study. Another reason may be to the hyperproduction of ESBL and AmpC coding genes or deletion/mutation in the OmpF and OmpC coding genes. ${ }^{51}$ Although the PCR-based method has the inherited disadvantages of being expensive and unable to detect novel genes, they remain the classical and reliable methods for better correlation of results with detailed phenotypic methods that have been used only as a primary screening for detection of carbapenemase enzymes. ${ }^{52-54}$

Table 4 Phenotypic Detection of Carbapenemase Producing of XDR GNB Isolates

\begin{tabular}{|c|c|c|c|c|c|c|}
\hline \multirow[t]{3}{*}{ Tested Isolate } & \multicolumn{2}{|c|}{$\begin{array}{l}\text { Modified Carbapenem } \\
\text { Inactivation Method }(\mathrm{mCIM})^{2}\end{array}$} & \multicolumn{2}{|l|}{ Blue-Carba Test $(\mathrm{BCT})^{3}$} & \multicolumn{2}{|c|}{ Combined Disk Test (CDT) ${ }^{4}$} \\
\hline & \multicolumn{2}{|l|}{ Meropenem Disk } & \multicolumn{2}{|l|}{ Imipenem Powder } & \multicolumn{2}{|l|}{$\begin{array}{l}\text { Imipenem/EDTA } \\
\text { (Class B) }\end{array}$} \\
\hline & $\begin{array}{l}\text { No of Cpo*/Total No } \\
\text { Tested }\end{array}$ & $\%$ & $\begin{array}{l}\text { No of Cpo*/Total No } \\
\text { Tested }\end{array}$ & $\%$ & $\begin{array}{l}\text { No of Cpo*/Total No } \\
\text { Tested }\end{array}$ & $\%$ \\
\hline E. coli & $3 / 3$ & 100 & $3 / 3$ & 100 & $2 / 3$ & 66.7 \\
\hline Klebsiella spp. & $14 / 14$ & 100 & $14 / 14$ & 100 & $8 / 14$ & 57.1 \\
\hline E. cloacae & $1 / 1$ & 100 & $\mathrm{I} / \mathrm{I}$ & 100 & $0 / 1$ & 0 \\
\hline A. baumannii & $|8 / 2|$ & 85.7 & $2|/ 2|$ & 100 & $|2 / 2|$ & 57.1 \\
\hline Pseudomonas spp. & $12 / 13$ & 92.3 & $12 / 13$ & 92.3 & $4 / 13$ & 30.8 \\
\hline
\end{tabular}

Abbreviations: Cpo, carbapenemase-producing organism; EDTA, ethylenediaminetetraacetic acid. 
Table 5 Summarization of Phenotypic and Genotypic Characters of the XDR GNB ( $n=52)$

\begin{tabular}{|c|c|c|c|c|c|c|c|}
\hline $\mathbf{N r}$ & $\begin{array}{l}\text { Isolate } \\
\text { No. }\end{array}$ & Isolate & $\begin{array}{l}\text { MIC Imipenem } \\
\mu \mathrm{g} / \mathrm{mL}\end{array}$ & $\begin{array}{l}\text { Combined } \\
\text { Disk Test }\end{array}$ & $\begin{array}{l}\text { Modified Carbapenem } \\
\text { Inactivation Test }\end{array}$ & $\begin{array}{l}\text { Blue- } \\
\text { Carba Test }\end{array}$ & $\begin{array}{l}\text { Carbapenemase } \\
\text { Genes }\end{array}$ \\
\hline 1 & $55 \mathrm{~A}$ & E. coli & 64 & - & + & + & blaKPC \\
\hline 2 & $84 S$ & Klebsiella spp. & 64 & - & + & + & blaOXA-48, blaKPC \\
\hline 3 & $36 \mathrm{M}$ & A. baumannii & 8 & - & + & + & blaOXA-48 \\
\hline 4 & 99 & $\begin{array}{l}\text { Pseudomonas } \\
\text { spp. }\end{array}$ & $>1024$ & - & - & + & blaKPC \\
\hline 5 & 83 & $\begin{array}{l}\text { Pseudomonas } \\
\text { spp. }\end{array}$ & $>1024$ & - & + & + & blaOXA-48, blaKPC \\
\hline 6 & 18 & $\begin{array}{l}\text { Pseudomonas } \\
\text { spp. }\end{array}$ & 256 & + & + & + & blaVIM \\
\hline 7 & $9 \mathrm{G}$ & A. baumannii & 256 & - & - & + & blaOXA-48 \\
\hline 8 & 50 & $\begin{array}{l}\text { Pseudomonas } \\
\text { spp. }\end{array}$ & $>512$ & - & + & + & blaOXA-48 \\
\hline 9 & $30 \mathrm{M}$ & A. baumannii & $>1024$ & + & + & - & blaVIM \\
\hline 10 & $78 S$ & $\begin{array}{l}\text { Pseudomonas } \\
\text { spp. }\end{array}$ & 32 & - & + & + & blaOXA-48 \\
\hline II & 100 & $\begin{array}{l}\text { Pseudomonas } \\
\text { spp. }\end{array}$ & 256 & - & + & + & blaOXA-48 \\
\hline 12 & $74 M$ & A. baumannii & 128 & + & + & + & blaOXA-48, blaKPC \\
\hline 13 & I09A & A. baumannii & 128 & - & + & + & blaOXA-48 \\
\hline 14 & $2^{*}$ & E. cloacace & 16 & - & + & + & $\begin{array}{l}\text { blaOXA-48, blaKPC, } \\
\text { blaVIM }\end{array}$ \\
\hline 15 & $6 M$ & A. baumannii & 32 & - & + & + & blaOXA-48, blaKPC \\
\hline 16 & 895 & Klebsiella spp. & 64 & - & + & + & blaOXA-48, blaKPC \\
\hline 17 & $8 I S$ & Klebsiella spp. & 8 & - & + & + & blaVIM \\
\hline 18 & $63 M$ & A. baumannii & 512 & - & + & + & blaOXA-48, blaKPC \\
\hline 19 & $30 \mathrm{G}$ & A. baumannii & 128 & - & + & + & blaKPC, blaVIM \\
\hline 20 & $100 M$ & A. baumannii & 128 & - & - & + & blaKPC \\
\hline 21 & $55 M$ & A. baumannii & $>1024$ & + & + & + & blaVIM \\
\hline 22 & 25 & Klebsiella spp. & 64 & - & + & + & blaKPC \\
\hline 23 & $34 \mathrm{E}$ & E. coli & 16 & - & + & + & blaKPC \\
\hline 24 & 1065 & Klebsiella spp. & 64 & - & + & + & blaKPC \\
\hline 25 & $28 \mathrm{M}$ & A. baumannii & $>1024$ & + & + & + & blaOXA-48, blaKPC \\
\hline 26 & $4^{*}$ & Klebsiella spp. & 256 & + & + & + & blaVIM \\
\hline 27 & $20 \mathrm{G}$ & A. baumannii & 32 & + & + & + & blaVIM \\
\hline 28 & $1 I^{*}$ & Klebsiella spp. & 265 & + & + & + & blaVIM \\
\hline
\end{tabular}

(Continued) 
Table 5 (Continued).

\begin{tabular}{|c|c|c|c|c|c|c|c|}
\hline $\mathbf{N r}$ & $\begin{array}{l}\text { Isolate } \\
\text { No. }\end{array}$ & Isolate & $\begin{array}{l}\text { MIC Imipenem } \\
\mu \mathrm{g} / \mathrm{mL}\end{array}$ & $\begin{array}{l}\text { Combined } \\
\text { Disk Test }\end{array}$ & $\begin{array}{l}\text { Modified Carbapenem } \\
\text { Inactivation Test }\end{array}$ & $\begin{array}{l}\text { Blue- } \\
\text { Carba Test }\end{array}$ & $\begin{array}{l}\text { Carbapenemase } \\
\text { Genes }\end{array}$ \\
\hline 29 & $7^{*}$ & Klebsiella spp. & 128 & + & + & + & blaOXA-48, blaKPC \\
\hline 30 & $92 \mathrm{~A}$ & Klebsiella spp. & 64 & + & + & + & $\begin{array}{l}\text { blaOXA-48, blaKPC, } \\
\text { blaVIM }\end{array}$ \\
\hline 31 & 19 & $\begin{array}{l}\text { Pseudomonas } \\
\text { spp. }\end{array}$ & 512 & + & + & + & blaOXA-48 \\
\hline 32 & $7 G$ & A. baumannii & 256 & + & - & + & blaKPC \\
\hline 33 & $42 M$ & A. baumannii & $>1024$ & + & + & + & blaOXA-48, blaKPC \\
\hline 34 & I3G & A. baumannii & $>1024$ & + & - & + & $\begin{array}{l}\text { blaOXA-48, blaKPC, } \\
\text { blaVIM }\end{array}$ \\
\hline 35 & $77 Y$ & $\begin{array}{l}\text { Pseudomonas } \\
\text { spp. }\end{array}$ & 16 & + & + & + & blaOXA-48, blaVIM \\
\hline 36 & $3 M$ & A. baumannii & 128 & + & + & + & blaOXA-48, blaKPC \\
\hline 37 & 33 & $\begin{array}{l}\text { Pseudomonas } \\
\text { spp. }\end{array}$ & 512 & - & + & - & blaKPC \\
\hline 38 & $99 \mathrm{~A}$ & E. coli & 64 & - & + & + & blaKPC \\
\hline 39 & 54 & $\begin{array}{l}\text { Pseudomonas } \\
\text { spp. }\end{array}$ & 512 & - & + & + & blaOXA-48 \\
\hline 40 & $14 M$ & A. baumannii & 128 & + & + & + & blaOXA-48, blaKPC \\
\hline 41 & $79 A$ & Klebsiella spp. & 512 & + & + & + & blaKPC \\
\hline 42 & $37 M$ & A. baumannii & 512 & + & + & + & blaVIM \\
\hline 43 & $9 *$ & Klebsiella spp. & 256 & + & + & + & blaKPC \\
\hline 44 & $34 M$ & A. baumannii & 512 & - & + & + & blaKPC \\
\hline 45 & $13 M$ & A. baumannii & $>1024$ & + & + & + & blaOXA-48, blaKPC \\
\hline 46 & $64 M$ & A. baumannii & 256 & - & + & + & $\begin{array}{l}\text { blaOXA-48, blaKPC, } \\
\text { blaVIM }\end{array}$ \\
\hline 47 & 1145 & Klebsiella spp. & 128 & + & + & + & blaOXA-48, blaKPC \\
\hline 48 & IIIS & $\begin{array}{l}\text { Pseudomonas } \\
\text { spp. }\end{array}$ & 256 & + & + & + & blaKPC \\
\hline 49 & 59 & $\begin{array}{l}\text { Pseudomonas } \\
\text { spp. }\end{array}$ & 32 & - & + & + & blaOXA-48 \\
\hline 50 & 1135 & Klebsiella spp. & 32 & - & + & + & blaOXA-48, blaKPC \\
\hline 51 & $112 \mathrm{~S}$ & Klebsiella spp. & 16 & + & - & + & blaVIM \\
\hline 52 & 51 & $\begin{array}{l}\text { Pseudomonas } \\
\text { spp. }\end{array}$ & 256 & - & + & + & blaOXA-48, blaKPC \\
\hline
\end{tabular}


Table 6 Association of MIC Level of Resistance and Carbapenemase Resistant Genes Among XDR GNB Isolates ( $\mathrm{n}-52$ ) and Statistically Significant Associations

\begin{tabular}{|c|c|c|c|c|c|c|}
\hline \multirow[t]{12}{*}{ MIC Resistance } & \multirow[t]{2}{*}{ Level } & \multicolumn{2}{|l|}{ blaKPC } & \multirow[t]{2}{*}{ Total $(n=52)$} & \multirow[t]{2}{*}{ Likelihood Ratio } & \multirow[t]{2}{*}{ Pearson Chi-Square } \\
\hline & & Negative & Positive & & & \\
\hline & $\mathrm{N}$ & 6 & 5 & 11 & 0.222 & 0.217 \\
\hline & $Y$ & 12 & 29 & 41 & & \\
\hline & & \multicolumn{2}{|c|}{ blaOXA-48 } & & & \\
\hline & & Negative & Positive & & & \\
\hline & $\mathrm{N}$ & 5 & 6 & \multirow{2}{*}{$\begin{array}{l}11 \\
41\end{array}$} & \multirow[t]{2}{*}{0.927} & \multirow[t]{2}{*}{0.927} \\
\hline & $\mathrm{Y}$ & 19 & 22 & & & \\
\hline & & \multicolumn{2}{|l|}{ blaVIM } & & & \\
\hline & & Negative & Positive & & & \\
\hline & $\mathrm{N}$ & 8 & 3 & 11 & 0.346 & 0.325 \\
\hline & $Y$ & 32 & 9 & 41 & & \\
\hline
\end{tabular}

Abbreviations: $N$, low level resistance $(n=I I)$; Y, high level resistance $(n=4 I)$.

\section{Conclusion}

In summary, this study shows the high prevalence of carbapenemase-encoding genes among XDR GNB in Egypt. Both blaKPC and blaOXA-48 like were found to be the most predominant CR genes. All XDR GNB were CPs as confirmed by phenotypic and genotypic methods. The high prevalence of CPs in Egypt with the limited potential therapeutic options necessitates an extreme concern and immediate intervention with effective antimicrobial stewardship programs to reduce the burden of $\mathrm{CR}$ along with limiting the spread of this nightmare emerging threat.

\section{Data Sharing Statement}

All the data supporting the findings are included in the manuscript.

\section{Ethical Clearance}

The study was approved by the Faculty of Pharmacy Cairo University Ethical Committee Nr. MI (2418) in April, 2019. A written informed consent was obtained from wither the patients or parents of the patients after clarifying them with the purpose of the study which was carried out in accordance with the guidelines outlined in the Declaration of Helsinki.

\section{Acknowledgments}

We would like to acknowledge the microbiology laboratories of New Kasr El Aini and El Demerdash Hospitals, Cairo, Egypt for providing us with the clinical isolates. We would like to acknowledge the Department of Microbiology and immunology, of both Faculty of pharmacy, Ain Shams University (ASU) and Ahram Candian University (ACU), Cairo, Egypt for providing support and facilities whenever needed. Also, I would like to acknowledge Miss Ann Elshamy, the assistant lecturer at the Microbiology and Immunology Department, Faculty of Pharmacy, Ain Shams University for providing help and support in performing PCR and agarose gel electrophoresis.

\section{Funding}

There is no funding to report.

\section{Disclosure}

The authors declare that they have no competing interests for this work.

\section{References}

1. Aslam B, Rasool M, Muzammil S, et al. Carbapenem resistance: mechanisms and drivers of global menace. In: Pathogenic Bacteria. IntechOpen; 2020. doi:10.5772/intechopen.90100

2. Elshamy AA, Aboshanab KM. A review on bacterial resistance to carbapenems: epidemiology, detection and treatment options. Future Sci OA. 2020;6(3):FSO438. doi:10.2144/fsoa-2019-0098

3. Biswas S, Bhat V, Kelkar R. Carbapenem-resistant Enterobacteriaceae: a serious concern in cancer patients. Access Microbiology. 2020;2(1):3. doi:10.1099/acmi.mim2019.po0008

4. Farhan SM, Ibrahim RA, Mahran KM, Hetta HF, Abd El-Baky RM. Antimicrobial resistance pattern and molecular genetic distribution of metallo- $\beta$-lactamases producing Pseudomonas aeruginosa isolated from hospitals in Minia, Egypt. Infect Drug Resist. 2019;12:2125. doi:10.2147/IDR.S198373 
5. Roberts RM, Bartoces M, Thompson SE, Hicks LA. Antibiotic prescribing by general dentists in the United States, 2013. J Am Dent Assoc. 2017;148(3):172-178. doi:10.1016/j.adaj.2016.11.020

6. Garg A, Garg J, Kumar S, Bhattacharya A, Agarwal S, Upadhyay GC. Molecular epidemiology \& therapeutic options of carbapenem-resistant Gram-negative bacteria. Indian J Med Res. 2019;149(2):285. doi:10.4103/ijmr.IJMR_36_18

7. Le L, Tran LK, Le-Ha TD, et al. Coexistence of plasmid-mediated mor-1 and blaNDM-4 genes in a Klebsiella pneumoniae clinical strain in Vietnam. Infect Drug Resist. 2019;12:3703. doi:10.2147/ IDR.S226612

8. Nordmann P, Gniadkowski M, Giske CG, et al. Identification and screening of carbapenemase-producing Enterobacteriaceae. Clin Microbiol Infect. 2012;18(5):432-438. doi:10.1111/j.14690691.2012.03815.x

9. Dortet L, Cuzon G, Ponties V, Nordmann P. Trends in carbapenemase-producing Enterobacteriaceae, France, 2012 to 2014. Eurosurveillance. 2017;22(6):30461. doi:10.2807/1560-7917. ES.2017.22.6.30461

10. Boutal H, Vogel A, Bernabeu S, et al. A multiplex lateral flow immunoassay for the rapid identification of NDM-, KPC-, IMP-and VIM-type and OXA-48-like carbapenemase-producing Enterobacteriaceae. J Antimicrob Chemother. 2018;73(4):909-915. doi:10.1093/jac/dkx521

11. Xin C, Xia Z, Li G. The impact of pharmaceutical interventions on the use of carbapenems in a Chinese hospital: a pre-post study. Infect Drug Resist. 2019;12:3567. doi:10.2147/IDR.S229009

12. Holt JG, Krieg NR, Sneath PH, Staley JT, Williams ST. The methanogens. In: Holt JG, Krieg NR, Sneath PHA, Staley JT, Williams ST, editors. Bergey's Manual of Determinative Bacteriology. 1994:719-736.

13. Magiorakos AP, Srinivasan A, Carey RB, et al. Multidrug-resistant, extensively drug-resistant and pandrugresistant bacteria: an international expert proposal for interim standard definitions for acquired resistance. Clin Microbiol Infect. 2012;18:268-281. 268-81. doi.10.1111/j.1469-0691.2011.03570.x

14. CLSI (2019). Performance Standards for Antimicrobial Susceptibility Testing. 29th ed. CLSI supplement M100S. Wayne, PA: Clinical and laboratory standards institute. CLSI [Internet]; 2019. Available from: https://clsi.org/media/2663/m100ed29_sample.pdf.

15. Yong D, Lee K, Yum JH, Shin HB, Rossolini GM, Chong Y. Imipenem-EDTA disk method for differentiation of metallo- $\beta$ lactamase-producing clinical isolates of Pseudomonas spp. and Acinetobacter spp. J Clin Microbiol. 2002;40(10):3798-3801. doi:10.1128/JCM.40.10.3798-3801.2002

16. Pires J, Novais A, Peixe L. Blue-carba, an easy biochemical test for detection of diverse carbapenemase producers directly from bacterial cultures. J Clin Microbiol. 2013;51(12):4281-4283. doi:10.1128/ JCM.01634-13

17. Murray PR, Baron EJ, Pfaller MA, Tenover FC, Yolken RH, Morgan DR. Manual of clinical microbiology (6th edn). Trends Microbiol. 1995;3(11):449.

18. Nordmann P, Naas T, Poirel L. Global spread of carbapenemase-producing Enterobacteriaceae. Emerg Infect Dis. 2011;17(10):1791. doi:10.3201/eid1710.110655

19. Poirel L, Hervé V, Hombrouck-Alet C, Nordmann P. Long-term carriage of NDM-1-producing Escherichia coli. J Antimicrob Chemother. 2011;66(9):2185-2186. doi:10.1093/jac/dkr236

20. Benmahmod AB, Said HS, Ibrahim RH. Prevalence and mechanisms of carbapenem resistance among Acinetobacter baumannii clinical isolates in Egypt. Microb Drug Resist. 2019;25(4):480-488. doi:10.1089/mdr.2018.0141

21. Feldman C, Shaddock E. Epidemiology of lower respiratory tract infections in adults. Expert Rev Respir Med. 2019;13(1):63-77. doi:10.1080/17476348.2019.1555040
22. da Silveira F, Nedel WL, Cassol R, Pereira PR, Deutschendorf C, Lisboa T. Acinetobacter etiology respiratory tract infections associated with mechanical ventilation: what impacts on the prognosis? A retrospective cohort study. J Crit Care. 2019;49:124-128. doi:10.1016/j.jcrc.2018.10.034

23. Chaturvedi R, Chandra P, Mittal V. Biofilm formation by Acinetobacter spp. in association with antibiotic resistance in clinical samples obtained from tertiary care hospital. Res J PharmTechnol. 2019;12(8):3737-3742. doi:10.5958/0974360X.2019.00620.6

24. Montefour K, Frieden J, Hurst S, et al. Acinetobacter baumannii: an emerging multidrug-resistant pathogen in critical care. Crit Care Nurse. 2008;28(1):15-25. doi:DOI.10.4037/ccn2008.28.1.15

25. Zhao D, Zuo Y, Wang Z, Li J. Characterize carbapenem-resistant Klebsiella pneumoniae isolates for nosocomial pneumonia and their Gram-negative bacteria neighbors in the respiratory tract. $\mathrm{Mol} \mathrm{Biol}$ Rep. 2019;46(1):609-616. doi:10.1007/s11033-018-4515-y

26. Tohamy ST, Aboshanab KM, El-Mahallawy HA, El-Ansary MR, Afifi SS. Prevalence of multidrug-resistant Gram-negative pathogens isolated from febrile neutropenic cancer patients with bloodstream infections in Egypt and new synergistic antibiotic combinations. Infect Drug Resist. 2018;11:791. doi:10.2147/IDR.S163293

27. Kamel NA, El-Tayeb WN, El-Ansary MR, Mansour MT, Aboshanab KM. Phenotypic screening and molecular characterization of carbapenemase-producing Gram-negative bacilli recovered from febrile neutropenic pediatric cancer patients in Egypt. PLoS One. 2018;13(8):e0202119. doi:10.1371/journal.pone.0202119

28. Rakhi NN, Alam AR, Sultana M, Rahaman MM, Hossain MA. Diversity of carbapenemases in clinical isolates: the emergence of blaVIM-5 in Bangladesh. J Infect Chemother. 2019;25(6):444-451. doi:10.1016/j.jiac.2019.01.010

29. Bayraktar B, Barış A, Malkoçoğlu G, Erdemir D, Kına N. Comparison of Carba NP-direct, carbapenem inactivation method, and $\beta$-CARBA tests for detection of carbapenemase production in Enterobacteriaceae. Microb Drug Resist. 2019;25(1):97-102. doi:10.1089/mdr.2017.0427

30. Cordeiro-Moura JR, Fehlberg LC, Nodari CS, et al. Performance of distinct phenotypic methods for carbapenemase detection: the influence of culture media. Diagn Microbiol Infect Dis. 2020;96 (1):114912. doi:10.1016/j.diagmicrobio.2019.114912

31. Takano C, Seki M, Kim DW, et al. Development of a novel loopmediated isothermal amplification method to detect Guiana extendedspectrum (GES) $\beta$-lactamase genes in Pseudomonas aeruginosa. Front Microbiol. 2019;10:25. doi:10.3389/fmicb.2019.00025

32. Queenan AM, Bush K. Carbapenemases: the versatile $\beta$-lactamases. Clin Microbiol Rev. 2007;20(3):440-458. doi:10.1128/CMR.0000107

33. Logan LK, Weinstein RA. The epidemiology of carbapenem-resistant Enterobacteriaceae: the impact and evolution of a global menace. J Infect Dis. 2017;215(suppl_1):S28-36. doi:10.1093/infdis/jiw282

34. Poirel L, Potron A, Nordmann P. OXA-48-like carbapenemases: the phantom menace. J Antimicrob Chemother. 2012;67(7):1597-1606. doi:10.1093/jac/dks121

35. Tzouvelekis LS, Markogiannakis A, Psichogiou M, Tassios PT, Daikos GL. Carbapenemases in Klebsiella pneumoniae and other Enterobacteriaceae: an evolving crisis of global dimensions. Clin Microbiolo Rev. 2012;25(4):682-707. doi:10.1128/CMR.05035-11

36. Majiduddin FK, Materon IC, Palzkill TG. Molecular analysis of beta-lactamase structure and function. Int $J$ Med Microbiol. 2002;292(2):127. doi:10.1078/1438-4221-00198

37. Li J, Li C, Cai X, et al. Performance of modified carbapenem inactivation method and inhibitor-based combined disk test in the detection and distinguishing of carbapenemase producing Enterobacteriaceae. Ann Transl Med. 2019;7(20):566. doi:10.21037/ atm.2019.09.43 
38. Ramadan RA, Gebriel MG, Kadry HM, Mosallem A. Carbapenemresistant Acinetobacter baumannii and Pseudomonas aeruginosa: characterization of carbapenemase genes and E-test evaluation of colistin-based combinations. Infect Drug Resist. 2018;11:1261. doi:10.2147/IDR.S170233

39. Abdulall AK, Tawfick MM, El Manakhly AR, El Kholy A. Carbapenem-resistant Gram-negative bacteria associated with catheter-related bloodstream infections in three intensive care units in Egypt. Eur J Clin Microbiol Infect Dis. 2018;37(9):1647-1652. doi:10.1007/s10096-018-3294-7

40. Papadimitriou-Olivgeris M, Bartzavali C, Lambropoulou A, et al. Reversal of carbapenemase-producing Klebsiella pneumoniae epidemiology from bla KPC-to bla VIM-harbouring isolates in a Greek ICU after introduction of ceftazidime/avibactam. $J$ Antimicrob Chemother. 2019;74(7):2051-2054. doi:10.1093/jac/dkz125

41. Stoesser N, Phan HT, Seale AC, et al. Genomic epidemiology of complex, multispecies, plasmid-borne bla KPC carbapenemase in Enterobacterales in the United Kingdom from 2009 to 2014. Antimicrob Agents Chemother. 2020;64(5). doi:10.1128/ AAC.02244-19

42. Abdelaziz MO, Bonura C, Aleo A, Fasciana T, Mammina C. NDM1-and OXA-163-producing Klebsiella pneumoniae isolates in Cairo, Egypt, 2012. J Glob Antimicrob Resist. 2013;1(4):213-215. doi:10.1016/j.jgar.2013.06.003

43. Aguirre-Quiñonero A, Martínez-Martínez L. Non-molecular detection of carbapenemases in Enterobacteriaceae clinical isolates. J Infect Chemother. 2017;23(1):1. doi:10.1016/j.jiac.2016.09.008

44. Koroska F, Göttig S, Kaase M, et al. Comparison of phenotypic tests and an immunochromatographic assay and development of a new algorithm for detection of OXA-48-like carbapenemases. J Clin Microbiol. 2017;55(3):877-883. doi:doi.10.1128/JCM.01929-16

45. Potron A, Poirel L, Rondinaud E, Nordmann P. Intercontinental spread of OXA-48 beta-lactamase-producing Enterobacteriaceae over a 11-year period, 2001 to 2011. Eurosurveillance. 2013;18 (31):20549. doi:10.2807/1560-7917.ES2013.18.31.20549

46. Evans BA, Amyes SG. OXA $\beta$-lactamases. Clin Microbiol Rev. 2014;27(2):241-263. doi:10.1128/CMR.00117-13
47. Tamma PD, Opene BN, Gluck A, Chambers KK, Carroll KC, Simner PJ. Comparison of 11 phenotypic assays for accurate detection of carbapenemase-producing Enterobacteriaceae. $J$ Clin Microbiol. 2017;55(4):1046-1055. doi:10.1128/JCM.02338-16

48. Gauthier L, Bonnin RA, Dortet L, Naas T. Retrospective and prospective evaluation of the carbapenem inactivation method for the detection of carbapenemase-producing Enterobacteriaceae. PLoS One. 2017;12(2):e0170769. doi:10.1371/journal.pone.0170769

49. Pasteran F, Veliz O, Ceriana P, et al. Evaluation of the Blue-Carba test for rapid detection of carbapenemases in gram-negative bacilli. J Clin Microbiol. 2015;53(6):1996-1998. doi:10.1128/JCM.03026-14

50. Pires J, Tinguely R, Thomas B, Luzzaro F, Endimiani A. Comparison of the in-house made Carba-NP and Blue-Carba tests: considerations for better detection of carbapenemase-producing Enterobacteriaceae. J Microbiol Methods. 2016;122:33-37. doi:10.1016/j. mimet.2016.01.002

51. Flury BB, Ellington MJ, Hopkins KL, et al. Association of novel nonsynonymous single nucleotide polymorphisms in ampd with cephalosporin resistance and phylogenetic variations in ampC, ampR, ompF, and ompC in Enterobacter cloacae isolates that are highly resistant to carbapenems. Antimicrob Agents Chemother. 2016;60(4):2383-2390. doi:10.1128/AAC.02835-15

52. Lari AR, Azimi L, Rahbar M, Alaghehbandan R, Sattarzadeh-Tabrizi M. First report of Klebsiella pneumonia carbapenemase-producing Pseudomonas aeruginosa isolated from burn patients in Iran: phenotypic and genotypic methods. GMS Hyg Infect Control. 2014;9(1). doi: $10.3205 /$ dgkh000226

53. Azimi L, Talebi M, Pourshafie MR, Owlia P, Lari AR. Characterization of carbapenemases in extensively drug resistance Acinetobacter baumannii in a burn care center in Iran. Int $\mathrm{J} \mathrm{Mol}$ Cell Med. 2015;4(1):46.

54. Chavda KD, Satlin MJ, Chen L, et al. Evaluation of a multiplex PCR assay to rapidly detect Enterobacteriaceae with a broad range of $\beta$ lactamases directly from perianal swabs. Antimicrob Agents Chemother. 2016;60(11):6957-6961. doi:10.1128/AAC.01458-16
Infection and Drug Resistance

\section{Publish your work in this journal}

Infection and Drug Resistance is an international, peer-reviewed openaccess journal that focuses on the optimal treatment of infection (bacterial, fungal and viral) and the development and institution of preventive strategies to minimize the development and spread of resistance. The journal is specifically concerned with the epidemiology of antibiotic resistance and the mechanisms of resistance development and diffusion in both hospitals and the community. The manuscript management system is completely online and includes a very quick and fair peerreview system, which is all easy to use. Visit http://www.dovepress.com/ testimonials.php to read real quotes from published authors. 